\title{
Villancicos que se cantaron en la Catedral de México, siendo maestro de capilla Francisco López Capillas: de la tradición oral a la tradición impresa
}

\section{Villancicos that were sung in the Cathedral of Mexico, being chapelmaster Francisco López Capillas: from the oral to the printed tradition}

\author{
Anastasia KRUTITSKAYA \\ (Universidad Nacional Autónoma de México) \\ anastasia_krutitskaya@enesmorelia.unam.mx \\ ORCID ID: 0000-0003-0152-3519
}

\begin{abstract}
The Villancico's pamphlets sung at RESUMEN: Los pliegos de villancicos que se Mexico Cathedral while Francisco López Capillas cantaron en la catedral de México durante el was its chapel master summarize numerous magisterio de capilla de Francisco López Capillas traditional lyrical manifestations such as folk songs, compendian numerosas manifestaciones líricas de games, riddles, lullabies, proverbs, sayings and even tipo tradicional, a decir, cancioncillas, juegos, preambles of tales and old wives' tales and advice. adivinanzas, nanas, proverbios, refranes, dichos y These are pages that were printed between 1650 and frases hechas, e, incluso, preámbulos de cuento o 1660. The four pages from 1672 and 1673 are styled principios de conseja. Se trata de pliegos que se as transitional works to a new verbal aesthetics in the imprimieron entre $1650 \mathrm{y} 1660$. Los cuatro pliegos composition of the villancicos: they are de 1672 y 1673 se estilan como obras de transición simultaneously witty, sometimes sharp, and jocular, para una nueva estética verbal en la composición de but they no longer maintain the popularizing flavor los villancicos: son a la vez ingeniosos, en of the previous group. This traditional character, ocasiones agudos, jocosos, pero ya no mantienen however, is not created from the simple inclusion of los aires popularizantes como el conjunto arriba folk songs in the villancicos, but it is based on the señalado. Este carácter tradicional, sin embargo, no principle of literary imitation. se construye a partir de la simple inclusión de las cancioncillas populares en los villancicos, se basa en el principio de imitación.
\end{abstract}

KEYWORDS: Religious villancicos, New Spain's PALABRAS-ClAVE: Villancicos religiosos, literatura literature, traditional poetry novohispana, lírica tradicional

Los pliegos de villancicos que se cantaron en la catedral de México durante el magisterio de capilla de Francisco López Capillas y en la época inmediatamente anterior a él se distinguen por una característica particular que, por un lado, los une a toda la producción villanciqueril de la época, pues en Puebla de los Ángeles también se observa el mismo fenómeno, y, por el otro, los deslinda de los villancicos posteriores a los años setenta del siglo XVII: la frecuente reutilización de diversas manifestaciones líricas de tipo tradicional, a decir, cancioncillas, juegos, adivinanzas, nanas, proverbios, refranes, dichos y frases hechas, e, incluso, preámbulos de cuento o principios de conseja. Se trata específicamente de impresos que vieron luz entre 1650, fecha que corresponde a nuestro 
primer pliego conocido de la Catedral de México, y 1660, último pliego que presenta estas características. Después de un lapso de 12 años, conservamos los pliegos de San Pedro y Asunción de 1672, anónimos, y los de San Pedro y Asunción de 1673, de Diego de Ribera y Fabián Juárez respectivamente. Los últimos cuatro pliegos se estilan como obras de transición para la siguiente generación estilística de villancicos: son a la vez ingeniosos, en ocasiones agudos, jocosos, pero ya no mantienen los aires popularizantes como el conjunto arriba señalado.

Francisco López Capillas nace en la Ciudad de México el 7 de octubre de 1614 y muere también en México el 18 de enero de 1674. Para el 11 de abril de 1654, cuando el cabildo de la Catedral de México le encomienda la composición de las chanzonetas del Corpus, Ascensión y San Pedro y lo nombra maestro de capilla y organista interino por la muerte de Fabián Pérez Ximeno (ACCMM, Actas del Cabildo, Libro 12, fol. 35v), López Capillas ya era un músico reconocido con amplia experiencia, de hecho, así los constatan las actas: «para reconocer las experiencias». Había ingresado a la capilla musical de la Catedral de México primero como ejecutante de bajón en 1636; a partir de 1641 ya se encuentra en la catedral de Puebla de los Ángeles como organista y bajonero, y desde 1645, además, actúa como cantor de la misma catedral, todo ello en la época de Juan de Palafox y Mendoza. Sin embargo, regresa a México en 1648 y a la capilla musical de la Catedral en 1654 (Reyes Acevedo, 2010).

Los primeros pliegos de villancicos de la Catedral de México fueron para la festividad de San Pedro y se imprimieron en 1650, 1651 y 1654 sucesivamente $^{8}$. Los tres pliegos salieron de la imprenta de la Viuda de Bernardo Calderón, pero no nos ha sido posible consultarlos directamente, pues pertenecen a una de las colecciones privadas. Las chanzonetas para san Pedro de 1654 fueron reproducidas parcialmente por Méndez Plancarte en los Poetas novohispanos, y las de 1650 y 1651, también de manera parcial, por Andrés Estrada Jasso. En la John Carter Brown Library se conservan los pliegos de San Pedro y de Navidad de 1657; de Navidad de 1658; de San Pedro de 1659 y de 1660; de San Pedro y de Asunción de 1672, así como de San Pedro y de Asunción de 1673 (BA69-.G643v). Los pliegos pertenecen al mismo volumen, que, a juzgar por las anotaciones manuscritas antiguas, fue adquirido por el Sagrario de la Catedral de México a mediados del siglo XVIII.

Las composiciones de estos impresos ilustran el complejo entramado del fenómeno cultural que fusiona la tradición oral y la tradición impresa. El impreso da cuenta de lo que se cantó en algún momento, testimonia una interpretación musical concreta; al mismo tiempo, el texto, preservado en papel, revela las preferencias de un momento específico por una determinada estética verbal. Las frecuentes divinizaciones de canciones populares sugieren que eran del agrado de todos, que lo que se esperaba de la fiesta y del villancico en este momento era reconocer su carácter tradicional. Este carácter tradicional, sin embargo, no se construye a partir de la simple inclusión de las cancioncillas populares en los villancicos, se basa en el principio de imitación.

\section{REELABORACIONES A LO DIVINO A PARTIR DE CANCIONCILLAS DE TIPO TRADICIONAL}

La serie de reelaboraciones empieza con las cancioncillas de tipo tradicional que aparecen insertas tanto en los estribillos como en las coplas de los villancicos religiosos. Uno de los ejemplos se encuentra entre las composiciones que se cantaron en la catedral

\footnotetext{
${ }^{8}$ Gabriel Saldívar los cita en su Bibliografía mexicana de musicología y musicografía (núms. 29, 30 y 31), basándose, a su vez, en el Suplemento Especial III a la Biblioteca Hispano Americana Septentrional (núms. 188 y 190) y en La imprenta en México de Medina (n. $\left.{ }^{\circ} 808\right)$.
} 
de México en la Navidad de 1657; sin embargo, el texto, al parecer, se compuso en Toledo, donde se presentó por primera vez también en Navidad, pero de 1643 (Biblioteca Nacional de España, VE/88/10). Su popularidad y posterior circulación se evidencia en otro pliego de Huesca de 1661 (Biblioteca Nacional de España, R/34981/11). Más que el estribillo «Amor profano muera, / muera por fugitivo», llaman la atención las coplas que se desarrollan a manera de preguntas y respuestas: «Molinico, ¿cómo te paras? / Porque los fríos me hielan el agua» ${ }^{9}$.

\section{Coplas}

1. - Molinico, ¿cómo te paras?

2. - Porque los fríos me hielan el agua.

1. - Molinico, ¿quién te detiene?

2. - Muchos ingratos que secan mis fuentes.

1. - Molinico, ¿cómo tan quedo?

2. - Porque me prenden el agua los hielos.

1. - Molinico, ¿quién te sustenta?

2. - Quien me le da qué moler a mi rueda.

1. - Molinico, ¿quién te la pica?

2. - Luego las pajas, después las espigas.

1.- Molinico, quién te da trigo?

2. - Tengo yo grano que brilla de limpio.

1. - Molinico, ¿dónde se siembra?

2. - Donde le dio sin arado la tierra.

1. - Molinico, ¿cómo se coge?

2. -Deja las mieses sin injuria las hoces.

(Villancicos..., 1657)

Margit Frenk registra la famosa cancioncilla conocida hasta el día de hoy «-Molinico, ¿por qué no mueles? / - Porque me beben el agua los bueyes» (NC 1162), que figura en obras de Orellana, Lope de Vega, Tirso de Molina y Quevedo. La versión que aparece en los pliegos de villancicos no implica divinización, sino que constituye un ejercicio de imitación, una invención a manera tradicional que circuló a lo largo de casi veinte años.

Otro ejemplo se encuentra en el estribillo de un villancico para san Pedro que se cantó en la catedral de México en 1659:

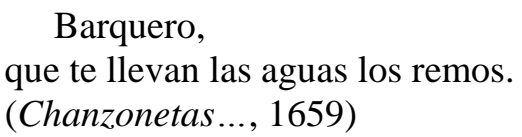

En realidad, es solo uno de los estribillos de una extensa ensalada con varios estribillos internos. Margit Frenk incluye esta cancioncilla en el Nuevo Corpus con los ejemplos de Góngora y Sor Juana (NC 954). Góngora la utiliza como estribillo del romance «Sin Leda y sin esperanza», y Sor Juana, en el Villancico VI del juego de san Pedro de 1683. Sin embargo, entre Góngora y Sor Juana existen dos testimonios más: uno de ellos pertenece al pliego de villancicos, escrito por Manuel de León Marchante, para la fiesta de Navidad que tuvo lugar en la catedral de Toledo en 1658 (Biblioteca Nacional de España, VE/88/24). El Villancico III de este pliego, «Envuelto en sus esperanzas», es una clara

\footnotetext{
${ }^{9}$ Todas las citas de fuentes antiguas fueron modernizadas de acuerdo con la ortografía actual.
} 
imitación de Góngora. El romance de Góngora repite el estribillo cada cuatro coplas y empieza así: «Sin Leda y sin esperanza / rompe en mal seguro leño /su serenidad al mar / y a la noche su silencio». El villancico de Toledo lo imita de una manera literal: «Envuelto en sus esperanzas, / busca el más seguro leño / la serenidad del mar, / de la noche en el silencio», y también repite el estribillo cada cuatro coplas. Al año siguiente el famoso estribillo llega a la catedral de México, pero el anónimo autor de la ensalada ya no imita a Góngora en las coplas, tampoco imita directamente el pliego de Toledo que era para la fiesta de Navidad; solo retoma el estribillo y lo aplica para la festividad de san Pedro. Sor Juana, a cambio, ni siquiera usa el octosílabo en las coplas, construye un ágil romancillo y mantiene la ingeniosa asociación del barquero con san Pedro. En el Nuevo Corpus Margit Frenk no registra menciones anteriores a Góngora de esta cancioncilla y es difícil saber si Góngora la retomó de la tradición oral o compuso un texto popularizante. Lo cierto es que la tradición villanciqueril impresa contribuyó a su difusión.

Otra curiosa imitación a lo divino tuvo lugar en la festividad de san Pedro en 1660:

Ay, que me llevan las olas del mar,

ay, Dios, si me volverán,

si me llevarán,

si me anegarán.

(Chanzonetas..., 1660)

La primera parte del estribillo fue retomada del pliego de villancicos para la fiesta de Navidad que se cantaron en la Capilla Real de Madrid en 1653: «iAy, que me llevan las olas del mar! / ¡Ay, Dios!, ¿si me llevarán?» (Biblioteca Nacional de España, VE/88/56). Margit Frenk la incluye como cancioncilla en el Nuevo Corpus con el número 962 bis, pero al mismo tiempo la deriva de otra canción conocida «-iOla, que me lleva la ola! / ¡Hola, que lleva la mar!» (NC 956) — que a su vez se halla en el Cancionero sevillano, en varias obras de Lope de Vega y en la mojiganga Triunfos de amor de Bernardo de Quesada. Frenk también trae a colación sus varias versiones a lo divino e imitaciones, incluyendo una de Góngora que forma parte de la ensalada «A la fuente va del olmo»: « Ola, que no llega la ola! / ¡Ola, que no quiere llegar!». A este propósito vendría al caso mencionar otro estribillo de México, cantado en la fiesta de San Pedro en 1660, donde se le da una nueva vuelta al tópico:

\footnotetext{
Dejalde pasar,

las olas de la mar,

las olas de la mar,

dejalde pasar.

(Chanzonetas..., 1660)
}

A pesar de contar con un impresionante respaldo de menciones que se presentan en el Nuevo Corpus, será preciso afirmar que los villancicos siguen su propio canal imitativo: generalmente en la Nueva España, al menos en esta época, no se imitan obras literarias que circulan en el entorno literario inmediato, los villancicos imitan otros villancicos, pues el material acumulado a ambos lados del océano permite hacerlo. Se imitan villancicos españoles que a su vez pueden, sí, basarse en el contexto literario general. 


\section{CANCIONCILLAS DE TIPO POPULAR AUTORIZADAS POR LA TRADICIÓN IMPRESA} VILLANCIQUERIL

Entre las canciones de tipo popular también valdría la pena citar aquellas que no figuran en otras fuentes literarias fuera del ámbito villanciqueril y que, sin embargo, han alcanzado cierta popularidad en los espacios eclesiásticos. Este es el caso del siguiente fragmento que pertenece al pliego de Navidad de 1657:

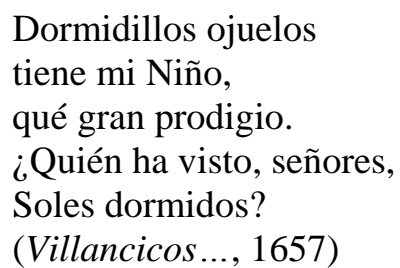

La cancioncilla, que en el pliego mexicano forma la segunda parte de un estribillo más extenso, se cantó por primera vez en la catedral de Sevilla en la Navidad de 1626 (Biblioteca Nacional de España, VE/1309/2). En el pliego sevillano la canción es el estribillo del tercer villancico y le siguen otras diez coplas: «Dormidillos ojuelos / tiene mi Niño, / ¿quién ha visto, señores, / soles dormidos?». Gutiérrez de Padilla, maestro de capilla de la Catedral de Puebla de 1629 a 1664, retomará el texto del pliego sevillano para componerle una nueva música, aunque en la partitura, conservada en la Colección Sánchez Garza del CENIDIM, INBA, solo aparecen las primeras cuatro coplas (CSG.189). No es posible afirmar quién fue el primero en reutilizar la cancioncilla en la Nueva España, Francisco López Capillas o Gutiérrez de Padilla, pero lo cierto es que el texto que utiliza López Capillas es un texto nuevo tanto en el estribillo como en las coplas, a excepción de esta precisa cancioncilla que se inserta en el estribillo. Con ello se puede evidenciar que la tradición villanciqueril también tiene la capacidad de producir y de difundir cancioncillas popularizantes propias con un alcance que cubre todo el territorio panhispánico.

\section{CANCIONCILLAS DE TIPO POPULAR}

El gusto por las cancioncillas tradicionales impone la necesidad de componer también cancioncillas de tipo popular, que no aparecen registradas en otras fuentes de la época, sin embargo, se caracterizan por una serie de rasgos estilísticos propios de los cantares populares. Entre otros, se puede señalar el estribillo del villancico de Navidad de 1659:

\footnotetext{
Airecico murmurador que entre las olas jugáis y voláis, ¿qué nuevas al mar lleváis? (Chanzonetas..., 1659)
}

El uso de sufijos diminutivos, símbolos exclusivos de antiguas canciones españolas - como el viento que se asoma en las canciones de muchacha e insinúa su libertadmanifiestan de nuevo el gusto por una estética popularizante en los espacios eclesiásticos. Otro estribillo de un villancico de San Pedro de 1660 da cuenta de ello:

Pájaro, que en seca rama

triste lloras, di ¿por qué?, 
que si lloras de amores,

yo te ayudaré.

(Chanzonetas..., 1660)

El pájaro, que en el cancionero popular puede aludir a la infidelidad, aquí se revela en metáfora de san Pedro que llora por su error después de negar conocer a Jesús. Estos últimos ejemplos de cancioncillas de tipo popular, que no aparecen en otras fuentes de la época y tampoco, en un principio, en otros villancicos, no son imitaciones, pues no contamos con antecedentes, tampoco son incorporaciones textuales de los cantares conocidos. Constituyen en sí un fenómeno característico de la última etapa de la época que nos ocupa e insinúan una especie de transición a un nuevo estilo de composición literaria.

\section{JUEGOS}

Diversos géneros o prácticas de carácter tradicional pueden llegar a cruzarse en un solo villancico. Así sucede con el estribillo del villancico para san Pedro de 1657 que consta de dos partes. Cada una de estas partes tiene su propia cabeza y una especie de copla. En la primera cabeza empieza hablando san Pedro, dirigiéndose a los niños e invitándolos a jugar:

\footnotetext{
Vayan adivinanzas con tiento, niños, pues que todo lo tengo por Jesucristo.
}

Y en seguida comienzan el juego:

1. - Adivina quién te dio que la mano te asentó. Adivina quién te da, Papa siendo viejo ya. Adivina quién te dio potestad de vice Dios. Adivina quién te da poder de abrir y cerrar. Adivina quién te dio el oficio de pastor. Adivina quién te da una mano de Satán.

Vayan adivinanças, etc. (Chanzonetas..., 1657)

El Diccionario de Autoridades registra la entrada Adivina quien te dio, que la mano te cortó en 1726 como:

juego que usan los muchachos para divertirse, el cual se hace poniéndose uno sentado: y al que por suerte le toca, se pone de rodillas y echa la cara sobre las manos del que está sentado, que con ellas se tapa los ojos, y de los demás que están puestos en fila enfrente, llama el que le ha tapado a uno con una seña, y viene. Y al que está de rodillas, que tiene una mano abierta y puesta sobre la espalda, le da un palmetazo y se vuelve a su lugar, y entonces le descubren y se levanta, diciéndole: «Adivina quien te dió, que la mano te 
cortó», y él va a escoger cuál es de ellos, y le trae, que si no lo acierta, se vuelve a poner otra vez.

El juego se menciona también en el Nuevo corpus de Margit Frenk: "Adivina quién te dio, / que la mano te assentó»(2148 A), retomado de los Juegos de Ledesma en el contexto del «Juego de "La palmada"» y «-Adivina quién te dio. I —La madre que te parió» (2148 B) de los Días geniales de Caro. También aparece en el Teatro universal de proverbios de Sebastián de Horozco:

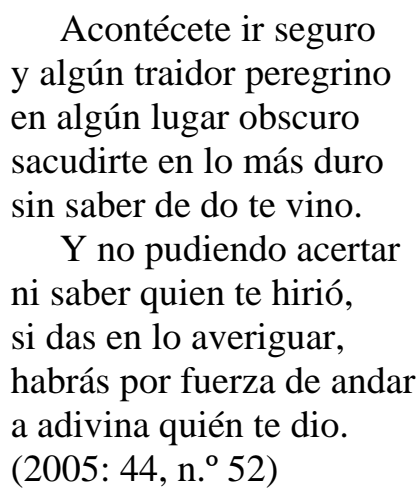

Pero en el estribillo del villancico el que habla es Jesucristo, Él es quien decide jugar a la palmada con San Pedro, como con un niño, para limpiar sus culpas, pues este último lo había herido en el corazón. La profanación del refrán bíblico con la posterior divinización de su versión popular ilustra las idas y vueltas entre tradiciones que podemos observar en las canciones de aquí y de allá. El desenlace de esta composición para san Pedro se da en la segunda parte del estribillo, donde encontramos también la asociación directa de la adivinanza con la quisicosa.

En un villancico de Navidad de 1658 podemos encontrar la alusión a otro juego, el de los toros:

Tod. - Toro fuera, toro fuera.

1. Hagan plaza, plaza, plaza.

Tod. -Afuera, afuera, afuera,

aparta, aparta, aparta.

2. - Ya el toril está abierto,

Jesús, que brama.

1. -Es un diablo el torillo, todos le llaman.

Tod. - To, to, to, to, to, to,

to, to, to, torillejo.

¡Oh, qué bravo que sale,

que brinca, que salta!

1. - ¡Guárdate, Antón, que te ha visto!

Tod. - Huye Pascual, guarda, guarda.

1. - ¡Oh, qué lance tan bueno,

el premio Pascual alcanza.

2. - Todos llaman al toro.

1. - Ay, que se encara.

Tod. - To, to, to, torillejo,

hucho ho, hucho ho, 
por aquí, por allá,

Jesús, que te alcanza.

2. - Corre, corre, Bartolo,

deja la capa.

Tod. - Hucho ho, hucho ho, torillejo,

ho, ho, ho,

denle la baya, ho, ho, ho,

que perdió el primer lance

de su esperanza.

Hucho ho, hucho ho, torillejo,

deje la plaza,

que si herró el primer vote,

perdió la gracia.

(Villancicos..., 1658a)

Aquí se da una especie de ambientación poética de lo que sucede en la plaza de toros. Ya Covarrubias lo explicaba:

Los españoles son apasionados por el correr de los toros y frisa mucho con los juegos teatrales de los romanos, en los cuales lidiaba diversas fieras en sus anfiteatros, y entre los demás toros, como consta de Marcial en algunos lugares suyos. Echaron con el rinoceronte un toro, y dice que le venteó en alto como si fuera dominguillo. [...] Y por esto sospecho que los romanos introdujeron el correr los toros en España (Cov. s.v. Toro).

En el texto el toro, sin embargo, representa al demonio que está siendo embestido por Jesús.

\section{ADIVINANZAS}

Como se mencionó unas líneas arriba, en la segunda parte del estribillo de san Pedro de 1657, después del juego de la Palmada, viene un desarrollo distinto que se basa en una continua tirada de adivinanzas:

Pues vayan agora

las adivinanzas, conozcan de Pedro grandezas y gracias.

¿Qué cosa y cosa tan maravillosa que le quiten las redes para que coja?

¿Qué cosa y cosa tan maravillosa que se arroja a mucha agua y teme la poca?

¿Qué cosa y cosa que en su navío se despoja seguro de su vestido?

¿Qué cosa y cosa que entrando en los mares el vestido se ponga para que nade?

¿Qué cosa y cosa que, siendo tan pobre, a sus pies le presenten todos sus dones?

¿Qué cosa y cosa de tan grande alteza que sus pies se levanten a su cabeza?

(Chanzonetas..., 1657) 
Las definiciones de la adivinanza y otros géneros afines en los diccionarios y preceptivas de la época, contradictorias y confusas a primera vista, brindan explicación a su frecuente utilización como recurso en los villancicos religiosos del siglo XVII. Adivinanza es «lo mismo que adivinación», dice el Diccionario de Autoridades. Y adivinación es «el acto de decir las cosas venideras, o conjeturar, o acertar las muy difíciles y escondidas». Sin embargo, en la redacción del Diccionario de la Real Academia Española de 1770 la adivinanza se define como «proposición enigmática dicha para que se adivine o descifre. Lo mismo que acertijo». De esta manera la adivinanza, el acertijo y el enigma se formulan como términos sinonímicos. Así, la adivinanza paulatinamente asimila el contenido del vocablo acertijo y solo hasta 1803 la explicación se reduce a «Lo mismo que acertijo» (Krutitskaya, 2016).

El acertijo, a su vez, se confunde con el enigma: «Acertijo. Uno como enigma, o duda intrincada y obscura, que se propone para que se descifre y declare: y porque el que la desata y declara da en el punto y acierta, se dijo Acertijo» (Aut.). Una de las formas de expresar el acertijo es la quisicosa; las quisicosas abundan en los villancicos dedicados a todo tipo de fiestas. Así será también el villancico de Navidad de 1658, donde el juego adivinancístico se anuncia en el estribillo y se desarrolla en las coplas.

\section{Estribillo}

Vaya de preguntas, vaya de juego, $\mathrm{y}$ alegremente la noche pasemos.

\section{Coplas}

1. - Dime, ¿qué cosa y cosa, que está mi remedio donde está la Rosa? 2. - Será la botica. 1. - No es sino el clavel, que nace a darme vida.

¿Qué encubre la tierra, que el Niño lo busca y en ella se encierra? 2. - Mas que son batatas.

1. - No son, sino tristes y cautivas almas. (Villancicos..., 1658)

Esta última secuencia de preguntas, además, recuerda la «Ensalada de las adivinanzas» de Fernán González de Eslava que expone la misma estructura: una introducción, un estribillo donde se proclama la reta de preguntas y las coplas en forma de pregunta, respuesta profana incorrecta y respuesta a lo divino correcta. La única diferencia consiste en el carácter de las preguntas y las respuestas profanas: González de Eslava recurre a adivinanzas tradicionales y los villancicos de mediados del siglo XVII plantean preguntas de tipo tradicional, mas no populares en sí. 


\section{REFRANES Y PROVERBIOS}

«Menos sabido es que muchos proverbios no solo tienen aire de canción, sino que son o han sido canciones, y que entre el mundo del refranero y el de la lírica musical hay como una zona intermedia en que ambos se encuentran, se mezclan, se funden y confunden», decía Margit Frenk en el memorable artículo «Refranes cantados y cantares proverbializados», donde analiza, por un lado, «ciertos refranes que solían cantarse»y, por el otro, «los cantares arrefranados o refranescos» (2006: 532-544). La relación entre los refranes y los cantares antiguos ha sido analizada posteriormente tanto por la propia Margit Frenk (2006 [1997]) como por Dutton (1989) o Bizzarri (2008) para el caso del romancero. No hay que olvidar tampoco el trabajo de María Begoña Barrio Alonso «Refranes y canciones», donde se analizan «refranes que forman parte de una canción, que están incluidos en ella», «que suele abarcar un verso o dos, no más, de la canción, que puede ir colocado al comienzo, al final, o en cualquier posición» (2001: 397) y que será la característica propia de los villancicos religiosos en general y, en particular, de las composiciones de la Catedral de México de los años cincuenta y sesenta del siglo XVII.

Entre los villancicos hay aquellos en los que de manera explícita se indica que lo que sigue o lo que se acaba de anunciar es un refrán o proverbio, como en uno de san Pedro de 1657:

Entre muchachos te veas, dice el adagio vulgar: salga acá, señor san Pedro, que hay mucho de bien y mal. (Chanzonetas..., 1657)

El adagio, como sabemos, «es lo mesmo que proverbio, conviene a saber, una sentencia breve, acomodada y traída a propósito, recibida de todos, que se suele aplicar a diversas ocasiones»(Cov.). Y el adagio vulgar «Entre muchachos de te veas» se encuentra documentado en distintas obras de teatro y recopilaciones poéticas del siglo XVII, por ejemplo, en la Comedia famoso del loco cuerdo de Lope de Vega: «[Danle los muchachos a Simeón de cañazos.] Simeón. Entre muchachos te veas. / Muchacho. I. El loco abad le mató, / ay, Lorenzo desdichado, / ¿qué haremos?» (Vega, 1616: 263). También Juan de Matos Fragoso lo trae a colación en la comedia El Fénix de Alemania: «Entre muchachos te veas, / que si padecer deseas, / este es el mayor tormento» (1670: 397). Lo mismo ocurre en la comedia El Apóstol de Salamanca de Felipe Sicardo: «No me está bien ir tan cerca / de quien gusta enloquecerse / con artificioso tema; / no la maldición me caiga / de entre muchachos te veas» (Sicardo, 1678: 51).

Otro ejemplo semejante se encuentra en un villancico de 1651; allí el estribillo anuncia que las coplas estarán construidas a partir de una cadena de refranes y así se desarrollan, introduciendo en cada nueva estrofa un refrán distinto:

\section{Estribillo}

Vaya de unos refranes, vaya de chanza, que está Pedro esta noche muy para gracias.

Coplas 


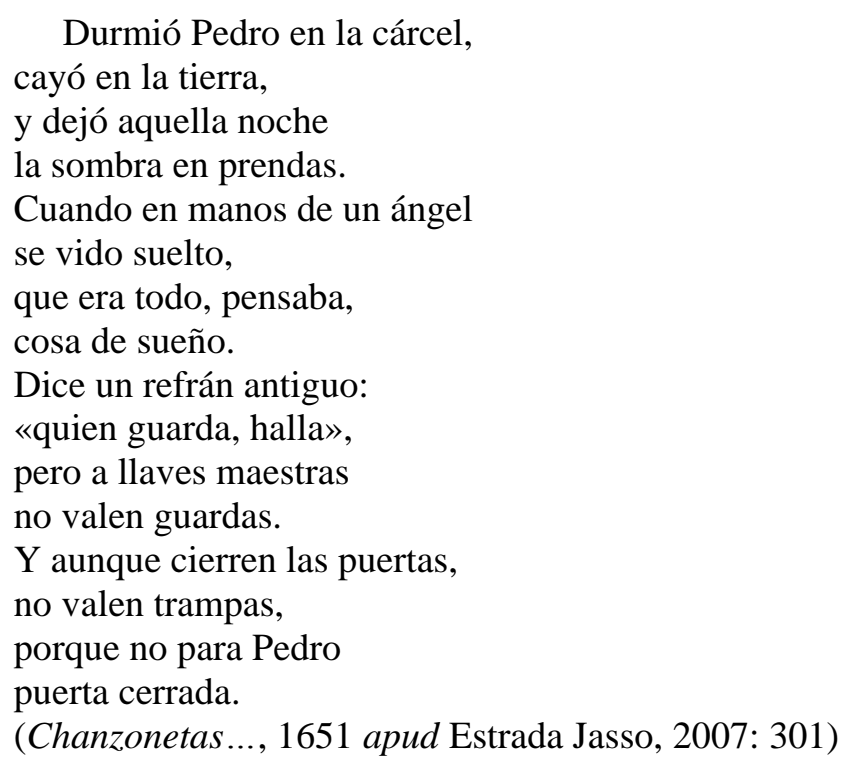

En cuanto al refrán de la primera copla «Quien guarda, halla», lo registra Correas en su Vocabulario en dos ocasiones: «Quien guarda, halla, y quien cría, mata» y «Quien guarda, halla, si la guarda no es mala». Aparece también en Sebastián de Horozco: «Quien guarda, halla, y guardaba la cazcarría» (1555: 107); Covarrubias lo menciona como proverbio «quien guarda halla» (s.v. Guardar), y en el Diccionario de Autoridades se anota en una entrada propia: «Quien guarda halla. Refrán que aconseja no se desperdicien las cosas, aunque parezcan inútiles, porque tal vez llega el caso de poder servir de algo». Cada una de las siguientes coplas del villancico presenta una selección de refranes que juega con algún aspecto de la vida de san Pedro, como pasa también en la primera copla: «pero a llaves maestras / no valen guardas».

Sin embargo, como en las canciones en general (Barrio Alonso, 2001: 400), es más frecuente encontrar villancicos con refranes y sin ninguna indicación de inicio. Su concentración aumenta de manera notable en los primeros villancicos de la Catedral de México que conocemos por Méndez Plancarte o Estrada Jasso. Así lo observamos en la siguiente composición de 1650:

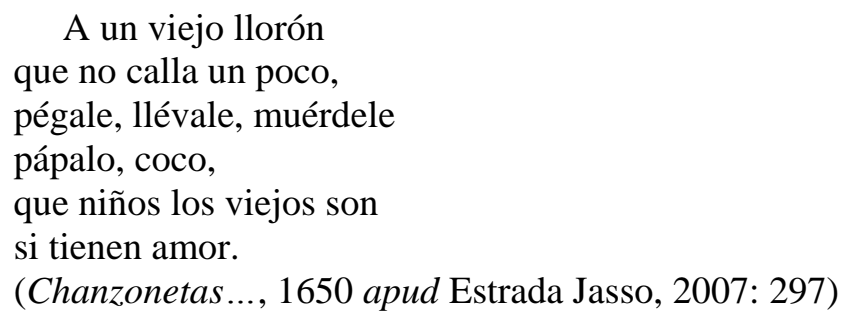

Gonzalo Correas asienta las siguientes frases proverbiales que en el texto se encadenan y convierten el estribillo en una continua perífrasis refranera: «Al hombre que fuere loco, tómale, llévale, pápale coco»; «Cómele, coco. (A los niños y aun a los grandes para darles miedo)»; «Pápele coco. (Así amedrentan a los niños)»; «La vejez tornó por los días en que nació. (Dice que los viejos vuelven a ser niños)», o «Volverse a la edad de los niños. (Los viejos que hacen niñerías)». Otro ejemplo será el villancico para san Pedro de 1654: 
En demandas y respuestas

Pedro y una fregoncilla andan, ella por cogerle, y él negando a pie juntillas.

- Yo le vi, yo le vi con el Nazareno, hétele aquí, que le vide como le veo y le miro como le vi! Hétele aquí. (Chanzonetas..., 1654 apud Méndez Plancarte, 1994: 106)

En el fragmento resalta el uso de refranes y frases proverbiales como «a pie juntillas» que metafóricamente vale «firmemente, con gran porfía y terquedad» (Aut.), «hétele aquí», etc. Cierran este apartado los versos extraídos de un villancico de Navidad de 1657:

Ya, blanco molinero, a nieve y a granizo, ninguno tan bien lleva el agua a su molino. (Villancicos..., 1657)

Hernán Núñez, en Refranes o preverbios en romance, indica que el refrán «Cada uno lleva el agua a su molino» (1555: 127) viene del italiano «Tuti tira el aqua al somolin». Mateo Alemán lo menciona en la Primera parte de Guzmán de Alfarache: «gobierna cada uno como mejor vaya el agua a su molino» (1992: 172). Lope de Vega lo expone en La quinta de Florencia: «pero una villaneja que no sabe / más que llevar el agua a su molino» (1995: 128). Y, finalmente, en el Vocabulario de refranes de Gonzalo Correas queda señalado en dos ocasiones: «Sabe traer el agua a su molino (del que sabe negociar su provecho)» (1906: 246) y «Traer el agua a su molino (encaminar las cosas a su provecho)» (1906: 425). La mayoría de los refranes y proverbios aquí aludidos permanecen en la tradición oral hasta el día de hoy.

\section{NANAS}

Las nanas, que en la actualidad conocemos como «canto con que se arrulla a los niños» (DRAE), circularon ampliamente en las fuentes impresas y manuscritas del siglo XVII, particularmente en las obras de teatro de autores como Lope de Vega o Tirso de Molina, de tal manera que en el Nuevo Corpus Margit Frenk reúne en el apartado «XII. Rimas de niños y para niños», especialmente en la primera sección llamada «1) Rimas para niños chiquitos», toda una serie de cancioncillas que identifica como canciones de cuna. Figura entre ellas la canción «Duérmete, niño, duérmete ya, / porque viene el coco y te comerá; / calla, muchacha, duérmete poco a poco, / guarda, niño, que viene el coco», retomada del pliego de villancicos de Navidad de la Catedral de Toledo de 1649. Esta misma cancioncilla, que permanece todavía, aunque con modificaciones, en el folclor actual del mundo hispánico, servirá como punto de partida para la composición de otro villancico novohispano:

El Coco. - Duérmete, Niño, duérmete ya, porque viene el Coco y te comerá:

A la rorro, rorro, ay que te comerá.

Coco. — ¿Quien llora aquí? Dénmele, me le comeré. 
Tod. - Vienes por el Niño?

Coco. -Sí.

Tod. - Ay de mí, ay que te comerá, duérmete, Niño, duérmete ya.

(Villancicos..., 1658a)

En las coplas se desarrolla un diálogo entre la feligresía (Todos) y el Niño Dios (Infante): los integrantes del coro siguen cantando la nana a lo divino y el Niño les da ánimos y ampara sus penas. Las canciones de cuna, tradicionales o no, serán una constante para los villancicos de Navidad de todo el siglo XVII e incluso parte del XVIII. En ciertas décadas incluso se compone una canción de cuna por juego y se convierte en un recurso popular y casi obligatorio para este ciclo de villancicos. La situación es más que propicia: el Niño, aunque se llame «dulce Jesús», sigue siendo niño; llora, tirita, no se calla, no se duerme, y la aclaración contextual se vuelve pertinente.

Cabe aclarar, sin embargo, que no se puede afirmar que las canciones de cuna pasaron a los villancicos directamente de la tradición oral sin una detallada reelaboración y adaptación al tema de la fiesta religiosa: en realidad son contrafacta a lo divino. Sucede que la reminiscencia de la canción entra en el circuito de las reelaboraciones mediante un marcador que permite reconocer la alusión («A la rorro, rorro», «Ce, ce, ce», «Quedito, pasito»). Si bien en la primera mitad del siglo XVII se puede aventurar que se retoman las canciones de la tradición de una manera literal, en la segunda mitad del siglo, especialmente a partir de los años setenta, son acaso palabras clave que remiten al cantar, que crean la ilusión de una canción de cuna, pero funcionan ya de manera independiente de la misma. Al mismo tiempo, en este, como en otros ejemplos, los villancicos novohispanos retoman patrones de imitación de villancicos españoles y ese traspaso crea tópicos específicos de la poesía villanciqueril.

\section{PREÁMBULO DE CUENTO O PRINCIPIO DE CONSEJA}

El preámbulo de cuento utilizado como estribillo se emplea en un villancico para Navidad de 1658:

Erase que se era, que norabuenaea.

Sus coplas de manera anafórica desarrollan una historia relacionada con el nacimiento de Jesús, de tal manera que cada copla comienza con «Érase...»:

1. -Érase en un portalillo un Niño, en quien vio la tierra un rostro como mil oros y un llanto como mil perlas.

2. -Érase en el mesmo sitio, así como macho y hembra, no quitando lo presente, dos famosísimas bestias. (Villancicos..., 1658a).

El preámbulo de cuento tomado como cancioncilla se encuentra citado en el Nuevo Corpus (1430 A), e incluso lo menciona Mariano Lambea, recordando un romance de 
Alonso de Ledesma incluido en los Juegos de Nochebuena y una «versión musicada» de Pujol (2002: 252-253).

\section{REFLEXIONES FINALES}

Los pliegos de villancicos de 1672 y 1673, cuatro en total, por un lado, corresponden a los últimos años del magisterio de capilla de Francisco López Capillas y, por el otro, representan un cambio estilístico importante. Mientras maduran las prácticas modernas de polifonía musical, se van desarrollando ingeniosas estructuras poéticas capaces de acoplarse a los nuevos requerimientos melódicos. Empiezan a escasear las coplas con su típica estructura de mudanza, enlace, vuelta. Los estribillos se desarrollan, se vuelven más largos, sirven para atrapar la atención de los oyentes y detener su mirada en ellos. Son más frecuentes ahora las coplas romanceadas que con el tiempo incorporan también estrofas de todo tipo. Se desarrolla el diálogo de carácter escénico. Para cuando aparece en la portada de un pliego de villancicos el nombre de Diego de Ribera (San Pedro, 1673), no queda rastro de la dulzura tradicional tan típica de las composiciones de los años cincuenta y sesenta. El pliego comienza, por primera vez, con una extensa dedicatoria; todas las coplas son romanceadas, acaso algunas son redondillas; todos los estribillos están desarrollados; incluso cuando, al último, introduce, por fin, una jácara, la compone con esdrújulos iniciales, es decir, procura encauzar su poesía en el terreno de los juegos de ingenio y evitar imitaciones de tipo tradicional.

Habría que precisar que los visos de la cultura popular no desaparecen del todo del panorama villanciqueril, pero cambian de tono y se sujetan en mayor grado del teatro breve. Sirve de ejemplo una de las redondillas del villancico para san Pedro de 1672:

Vestido deja la popa

Pedro para echarse al mar, que la gala del nadar viene a ser guardar la ropa.

(Chanzonetas..., 1672)

Si bien se reconoce el refrán «El mejor nadar es guardar la ropa», señalado también por Correas en el Vocabulario, su entorno inmediato es una agudeza con uso de hipérbaton. Otro villancico de Diego de Ribera empieza con un verso de tono popularizante «Ay Jesús, que me mate de amores» pero su desarrollo ya no conserva ningún recuerdo de tipo tradicional.

Ay Jesús, que me mate de amores, ay mi Dios, que la vida me roba, que se parte y se ausenta, Jesús qué gloria: que se nos pierde, que se remonta, y subiendo a los cielos la dulce esposa, halla en trono de luzes

silla de antorchas.

(Villancicos..., 1673a).

En el mismo juego de 1673 Diego de Ribera compone unas seguidillas con ecos, que de popular solo mantienen la forma.

Palomita graciosa, divina garza, 
donde vas por las cumbres, que te levantas:

para, para,

que tu voz me suspende,

me eleva, me abrasa:

para, para,

y al compás de mis ecos

oye mis ansias.

(Villancicos..., 1673a)

Las transformaciones estilísticas que se dejan ver en los últimos pliegos de Francisco López Capillas son sorprendentes. Se han repasado aquí ejemplos de cancioncillas, juegos, adivinanzas, nanas, proverbios, refranes, dichos y frases hechas y preámbulos de cuento o principios de conseja que abundan en los villancicos de la Catedral de México de los años cincuenta y sesenta del siglo XVII. Todos ellos, sin duda, contribuyen a cultivar un particular gusto por lo popular, un gusto que, de toda la poesía que se publica en estos años en la Nueva España, se manifiesta fundamentalmente en los villancicos religiosos. Ese gusto, en fin, no es el gusto de lo popular, sino el gusto de lo popularizante. La poesía villanciqueril, además, se constituye como vía de circulación de cantarcillos propios, congruentes con los propósitos de la fiesta. A excepción de los refranes que siempre han sido y serán del dominio público, las otras manifestaciones líricas populares tienen como principio natural de la transmisión la imitación: o se imitan textualmente, con mayor o menor grado de transformación, o se imitan desde la estructura. Sea como sea, las imitaciones se trasladan de villancico a villancico, es decir, la poesía villanciqueril llega a cimentar una tradición propia del género. 


\section{REFERENCIAS BIBLIOGRÁFICAS}

Alemán, Mateo (1992): Primera parte de Guzmán de Alfarache, José María Micó (ed.), Madrid, Cátedra.

BARRIO AlONSO, María Begoña (2001): «Refranes y canciones», en Lyra minima oral. Los géneros breves de la literatura tradicional: actas del Congreso Internacional celebrado en la Universidad de Alcalá, 29-30 Octubre 1998, Carlos Alvar, Cristina Castillo, Mariana Masera y José Manuel Pedrosa (eds.), Alcalá de Henares, Universidad de Alcalá.

BIZZARRI, Hugo O. (2008): «Refranes y romances: un camino en dos direcciones», Bulletin Hispanique, 110, 2, pp. 407-430.

DOI: https://doi.org/10.4000/bulletinhispanique.743

CORREAS, Gonzalo (1906): Vocabulario de refranes y frases proverbiales y otras fórmulas comunes de la lengua castellana en que van todos los impresos antes y otra gran copia, Madrid, Establecimiento tipográfico de Jaime Batés.

CovarRubias OrozCo, Sebastián de (1611): Tesoro de la lengua castellana o española, Madrid, Luis Sánchez.

Diccionario de Autoridades (1726-1739): 4 vols. Madrid, Real Academia Española.

DutTon, Brian (1989): «Proverbs in Fifteenth-Century Cancioneros», en The Age of the Catholic Monarchs, 1474-1516: Literary Studies in Memory of Keith Whinnom, Alan David Deyermond y Ian Richard MacPherson (eds.), Liverpool, Liverpool UP.

ESTRADA JASSO, Andrés (2007): El villancico virreinal mexicano, México, Gobierno del Estado de San Luis Potosí, Archivo Histórico.

FRENK, Margit (2006): Poesía popular hispánica: 44 estudios, México, FCE.

FRENK, Margit (2003): Nuevo Corpus de la antigua lírica popular hispánica, siglos XV a XVII, México, UNAM, El Colegio de México, FCE.

Horozco, Sebastián de (2005): Teatro universal de proverbios, José Luis Alonso Hernández (ed.), Salamanca, Universidad de Salamanca.

KRUTITSKAYA, Anastasia (2016): "“Vayan adivinanzas con tiento, niños": quisicosas y villancicos novohispanos», en Odres nuevos: retos y futuro de la literatura popular infantil, Cristina Cañamares Torrijos, Ángel Luis Luján Atienza, César Sánchez Ortiz (coords.), Cuenca, Universidad de Castilla-La Mancha.

LAMBEA, Mariano (2002): «Estribillos populares puestos en música en villancicos y romances sacros y profanos de finales del siglo XVI y principios del XVII», Patrimonio musical: artículos de patrimonio etnológico musical, pp. 245-265.

Matos Fragoso, Juan de (1670): El Fénix de Alemania, en Parte treinta y tres de comedias nuevas, nunca impresas, escogidas de los mejores ingenios de España, Madrid, Ioseph Fernandez de Buendia.

MedinA, José Toribio (1908-1911): La imprenta en México (1539-1821). 8 vols. Santiago de Chile, Casa del autor.

MÉndez PlanCARTE, Alfonso (1995): Poetas novohispanos. Segundo siglo (1621-1721), México, UNAM.

NúÑEZ, Hernán (1555): Refranes o proverbios en romance, Salamanca, Iuan de Canoua. 
ReYes ACEVEDO, Ruth Yareth (2010): «Francisco López Capillas, un músico del siglo XVII», Heterofonía, 142, pp. 55-90.

SALDÍvAR, Gabriel (1991): Bibliografía Mexicana de Musicología y Musicografía. Tomo 1. México, CENIDIM.

SANCHA, Justo de (1855): Romancero y cancionero sagrados. Colección de poesías cristianas, morales y divinas, sacadas de las obras de los mejores ingenios españoles, Madrid, Rivadeneyra.

SiCARDO, Felipe de (1678): El apóstol de Salamanca. En Parte cuarenta y cuatro de comedias nuevas, nunca impresas, escogidas de los mejores ingenios de España, Madrid, Roque Rico de Miranda.

Suplemento especial III a la Biblioteca Hispano Americana Septentrional que escribiera el Dr. Don José Mariano Beristain de Souza. Contiene: 500 nuevos impresos de F.G. de Cossio. Bibliografía de publicaciones periódicas o noticiosas. Escritores nacidos, avecindados o que escribieron... Autores por profesión u orden religiosa. Autores por nacionalidad o país de origen. Y otros índices diversos [1947]: Vol. 8. México, Ediciones Fuente Cultural.

Tello, Aurelio, Hurtado, Nelson, Morales, Omar y Bárbara PÉREZ (2017): Colección Sánchez Garza. Estudio documental y catálogo de un acervo musical novohispano. 2 Tomos. México, INBA, ADABI.

VegA, Lope de (1995): La quinta de Florencia, Debra Collins Ames (ed.), Kassel, Reichenberger.

VEGA, Lope de (1616): Del loco cuerdo. En Flor de las comedias de España de diferentes autores. Quinta parte. Recopiladas por Francisco de Ávila, vecino de Madrid, Barcelona, Sebastian de Cormellas al Call.

\section{FUENTES}

ACCMM, Actas del Cabildo, Libro 12.

\section{PLIEGOS DE VILLANCICOS}

Villancicos que se cantaron en la santa iglesia mayor en los maitines solemnes del santísimo Nacimiento de Nuestro Señor (1626), Sevilla, Juan Cabrera.

Villancicos que se cantaron en la santa iglesia de Toledo, primada de las Españas en los maitines del Nacimiento de Nuestro Señor Jesucristo (1643), [Toledo], s.n.

Villancicos que se cantaron en la santa iglesia de Toledo, primada de las Españas en la Nochebuena (1649), Toledo, Juan Ruiz de Pereda.

Villancicos que se han de cantar en la Capilla Real de su Majestad la noche de Navidad (1653), [Madrid], s.n.

Chanzonetas que se cantaron en la santa iglesia catedral de México en los maitines del gloriosísimo príncipe de la Iglesia el señor san Pedro (1657), México: Viuda de Bernardo Calderón.

Villancicos que se cantaron en la santa iglesia catedral de México la noche de Navidad (1657), México, Viuda de Bernardo Calderón. 
Villancicos que se cantaron en la santa iglesia catedral de México la noche de Navidad (1658a), México, Viuda de Bernardo Calderón.

Villancicos que se cantaron la Nochebuena en la santa iglesia de Toledo (1658b), Toledo, Francisco Calvo.

Chanzonetas que se cantaron en la santa iglesia catedral de México en los maitines del gloriosísimo príncipe de la Iglesia el señor san Pedro (1659), México, s. n.

Chanzonetas que se cantaron en la santa iglesia catedral de México en los maitines del gloriosísimo príncipe de la Iglesia el señor san Pedro (1660), México, Viuda de Bernardo Calderón.

Villancicos que se cantaron la noche de Navidad en la santa iglesia catedral de Huesca (1661), Huesca, Juan Francisco de Larumbe.

Chanzonetas que se cantaron en la santa iglesia catedral de México a los maitines del gloriosísimo príncipe de la Iglesia el señor san Pedro (1672), México, Viuda de Bernardo Calderón.

Villancicos que se cantaron en la santa iglesia metropolitana de México en honor de María santísima Madre de Dios en su Asunción triunfante (1672), México, Viuda de Bernardo Calderón.

Villancicos que se cantaron en la santa iglesia catedral de México a los maitines del glorioso príncipe de la Iglesia el señor san Pedro (1673a), México, Viuda de Bernardo Calderón.

Villancicos que se cantaron en la santa iglesia metropolitana de México en honor de María Santísima Madre de Dios en su Asunción triunfante (1673b), México, Viuda de Bernardo Calderón.

Fecha de recepción: 29 de agosto de 2019

Fecha de aceptación: 30 de agosto de 2019 